\title{
The prevalence of developmental dyscalculia in Brazilian public school system
}

\author{
A prevalência da discalculia do desenvolvimento no sistema publico de educação brasileiro \\ José Alexandre Bastos, Angela Maria Traldi Cecato, Marielza Regina Ismael Martins, Kelly Regina Risso \\ Grecca, Rafael Pierini
}

\begin{abstract}
The goal of the study was to assess public school children at the end of the first stage of elementary school. We used a protocol applied concurrently with a writing test in the form of an unexpected activity in 28 public schools; 2,893 children assessed, 687 exhibited performance below 58 points, 184 were excluded due to change of address or lack of consent; 503 children subjected to a test of intellectual capacity and reading assessment and 71 considered intellectually disabled were excluded. 226 (7.8\%) children, who could read, write, and had normal intellectual level, met the criteria of developmental dyscalculia (DD), 98 female and 128 male. The most influential factors in the prevalence were socioeconomic levels of the schools neighborhood, education level of parents, and being male, as demonstrated by the odds ratio and multiple logistic regression analysis. Further studies should be done so that educational policies are taken.
\end{abstract}

Keywords: dyscalculia, epidemiology, prevalence, children, socioeconomic status, multivariate analysis.

\section{RESUMO}

Este estudo teve como objetivo avaliar crianças da rede pública no final da $1^{\text {a }}$ etapa do ciclo fundamental; com um protocolo aplicado em forma de atividade surpresa em 28 escolas públicas, concomitantemente a uma prova de escrita: Das 2893 crianças avaliadas, 687 tiveram rendimento abaixo de 58 pontos, 184 foram excluídas por mudança de domicilio ou por falta de consentimento; 503 submetidas a um teste de avaliação intelectual e de leitura, 71 consideradas intelectualmente deficientes foram excluídas do estudo. 226 (7,8\%) sabiam ler e escrever e intelectualmente normais, preenchendo os critérios para o diagnóstico de discalculia do desenvolvimento (DD), 98 do sexo feminino e 128 masculinos. Fatores que mais influenciaram na prevalência da DD foram os níveis socioeconômicos do bairro da escola, nível de escolaridade dos pais e sexo masculino, demonstrados pela Odds Ratio e Analise de regressão logística múltipla. Mais estudos devem ser realizados para que políticas educacionais sejam tomadas.

Palavras-chave: discalculia, epidemiologia, prevalência, crianças, nível socioeconômico, analises multivariadas.

Developmental dyscalculia (DD) is defined as a specific disability in learning arithmetic occurring in individuals with normal intellectual level, without neurological, psychiatric, sensory, and emotional disorders ${ }^{1}$. Its prevalence is controversial, since some studies claim that DD is a rare disorder with an occurrence of $1 \%^{2}$; whereas other studies regard it as being frequent, ranging from 3 to $6 \%^{3}$.

"The role of the physician in the management of dyscalculia begins in the diagnostic phase by establishing whether the learning disability is a primary, symptomatic, or comorbid entity. Physicians, with their inherent authority, are often the appropriate member within the multidisciplinary team to discuss with parents the nature and ramifications of the cognitive disability affecting their child. They can guide both child and parents through the maze of expert assessments and multitude of therapeutic options while providing explanations regarding the neurologic underpinnings of the disorder and its familial-genetic implications"4.

In Brazil, quantitative assessments School performance assessment system of the State of São Paulo (SARESP) and (Elementary Education Assessment System). Brazilian Ministry of Education (SAEB) have been conducted on arithmetic skills corresponding to the curriculum, without considering the various causes that have led to the bad results found. International studies, such as the Program for International Student Assessment (PISA) carried out periodically by the Organization for Economic Co-operation and Development (OECD), confirm the low outcome accomplished by Brazilian children in arithmetic. In addition, there are no studies on the prevalence of DD. Research should be conducted in order to standardize the diagnosis and develop appropriate intervention strategies.

Projeto Gato de Botas, São José do Rio Preto SP, Brazil.

Correspondence: José Alexandre Bastos; Avenida Brigadeiro Faria Lima, 5622;15090-000 São José do Rio Preto SP, Brasil; E-mail: jose.alexandre.basto@terra.com.br Conflict of interest: There is no conflict of interest to declare.

Received 30 July 2015; Received in final form 27 October 2015; Accepted 17 November 2015. 
In recent years, neuroscience in education has been assuming an increasingly important role. It involves professionals from various fields such as neurologists, psychiatrists, psychologists, speech pathologists, neuropsychologists, occupational therapists, educational psychologists, and teachers, whose goal is to understand how the brain learns in order to provide better teaching. The advancement of neuroscience with genetic and neuroimaging studies show that the DD is a genetic disorder with neurobiological bases and strong environmental influence. The great challenge is exactly how to proceed with this new knowledge of functional neuroimaging, electromagnetography, and computer sciences, so that teaching methodologies can be developed. The DD has the same prevalence of the disorder attention deficit and dyslexia ${ }^{5}$, though it causes major impediment in professional and socioeconomic development of the individual, the number of studies about them is lower, making their diagnosis is underestimated with consequent fewer of people treated. The present study correlates DD with social conditions of the neighborhood in which the schools were located, sex, education level of the parents, and coexistence with reading and writing disabilities.

\section{METHOD}

São José do Rio Preto is a city located in the northwest of the State of São Paulo, Brazil. It has about 480,000 inhabitants with human development index considered above the Brazilian average. The present study assessed 2,893 children of a total of 3,093 who had completed the first stage of elementary education ( $5^{\text {th }}$ grade) in the public school network. The schools were divided into group A, B, C, D and E following the criteria of family vulnerability indicator system (SIFV) ${ }^{6}$.

The study was approved by the Ethics Committee of São José do Rio Preto Medical School (FAMERP) under no. 5685/2009, Opinion no. 396/2009. It is a descriptive, exploratory and cross-sectional study using a convenience sample.

A mathematics protocol was used (Bastos, 2003; adapted from Grafman and Boller's modified protocol) $)^{5}$, since it allows simultaneous assessment of a large population. The skills assessed were: lexical skill in symbolic and writing form; syntax skill in the production of dozens, hundreds, thousands, and ten thousands in symbolic and writing form; quantifying high and low numbers; performing the four fundamental operations with simple and complex calculations; and resolution of concrete, semi-concrete, and abstract problems.

This protocol was composed of 50 questions allowing the maximum score of 100 points.

\section{Procedure of the first step}

In the first step of the study, the protocol was applied in the form of an unexpected activity, on the same day, at the beginning of the 2012 school year, in children who had completed the first stage of elementary education ( $5^{\text {th }}$ grade) in the 2011 school year. The students were asked to produce a text from three words. They were given 60 minutes for completing the activity and the only exclusion criterion was the absence of the children.

The activity was corrected by the team of the Puss in Boots Project which is a partnership between Medical School of S.J. of Rio Preto SP. and the Municipal Secretary of Education for diagnosis and intervention in children with specific learning disorder. The cut-off score to consider children's performance below expected was 58 points out of 100 possible. The outcome was considered two levels below the expected for this school level. At this time, writing skills were also corrected.

\section{Procedure of the second step}

At the beginning of the 2012 school year and after the parents had signed an informed consent from, Wechsler Intelligence Scale for Children-Revised (WISC-R) ${ }^{7}$ (cubes and vocabulary) was used to assess the presumed intellectual level. At this time, reading skills were assessed by means of a text compatible with the educational level and 184 children were not assessed due to change of address, or because the parents had not signed the informed consent form.

The data obtained include: (a) identification of children and school; (b) ages (c) sex; (d) fathers' education; (e) mothers' education; ( $f$ ) social level of the neighborhoods in which the schools were located; (g) quantitative outcome; (h) qualitative outcome; (i) whether the children could write; (j) whether the children could read; (k) intellectual level (Tables 1 and 2).

\section{Statistical analysis}

The descriptive statistical analysis of the variables under study was initially performed and the chi-square test was subsequently used for comparing the categorical variables. Fisher's exact test with Yates' correction and the calculation of the odds ratio (OR) were used for two-by-two comparisons.

The multiple logistic regression (LR) model was used to confirm the influence of sex, social level of the schools, and parents' education level on dyscalculia, considering as outcome individuals with dyscalculia that scored below 58 points, could read and write, and had normal intellectual level. The backward LR method was used for the selection, and 5\% significance level ( $p$-value $\leq 0.05$ ) and the Statistical Package for the Social Sciences software (SPSS version 22.0) were used in all comparisons.

\section{RESULTS}

Multiple logistic regressions were used considering as an outcome children exhibiting dyscalculia or not, who scored below 58 points and could read and write. The most accurate model included all the predictor variables assessed and 
showed an $\mathrm{R}^{2}$ value of $45.6 \%$ and general hit power of $97 \%$. All variables assessed as predictors or explanatory variables influenced the occurrence of dyscalculia. The mothers' education level was the variable that best explains dyscalculia $(\mathrm{OR}=8.764)$, followed by sex $(\mathrm{OR}=7.213)$, and social level of the neighborhood in which the schools were located $(\mathrm{OR}=6.871)$. The fathers' education level was the one that least influenced the proposed model $(\mathrm{OR}=0.661)$ - Figure 1 , Figure 2, Figure 3, Figure 4, Table 3, Figure 5, Figure 6, Table 4.

\section{DISCUSSION}

In 1957, Russia celebrated the success of the launch of the Sputnik satellite into space ${ }^{8}$, while the United States suffered a series of failures, which lead President Eisenhower to summon his advisors for explanations. The conclusion is that, at the time, the American education was geared toward professionalization and training of technicians, lacking highly qualified teachers in mathematics to teach a number of high-level students needed to meet the demand. This fact changed the direction of mathematics teaching in the United States and serves as a present-day reflection on the need for changes in our teaching.

Table 1. Demographic characteristics of the sample ( $n=2,893$ ). Shows the frequency of children assessed in the present study with respect to sex and level of social vulnerability in the neighborhood in which the schools were located. Age: average in years \pm SD $=10.8 \pm 0.72$

\begin{tabular}{lc}
\hline VARIABLES & $\%$ \\
\hline Sex & \\
Female & $49.3(n=1,428)$ \\
Male & $50.7(n=1,465)$ \\
Social level of the Schools $(n=29)$ & \\
A & 0 \\
B & 10.5 \\
C & 31.5 \\
D & 58 \\
E & 0 \\
\hline
\end{tabular}

SD: standard deviation; A: safety situation; B: very low vulnerability; C: low vulnerability; D: medium vulnerability; E: high vulnerability.

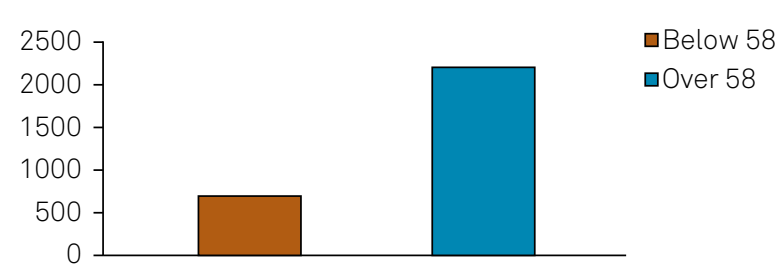

Figure 1. Results of the Mathematics Protocol (Bastos, 2003; adapted from Grafman and Boller's modified protocol) ${ }^{5}$ ( $n=2,893$ ), shows that the outcome of 687 children was below 58 points.
The present study shows that the prevalence of DD in São José do Rio Preto was $7.8 \%$. Therefore, it is necessary to warn that this number-slightly above the world averagerepresents important social problems. The analysis of the results showed greater prevalence among children studying in schools located in neighborhoods of greater vulnerability, with parents of low education level, and predominance of occurrence in male individuals.

The comparison between the results of the present study with those found by other researchers reveals that the numbers are not so different. Shalev ${ }^{4}$ showed a prevalence of $6.5 \%$, which is similar to dyslexia and attention deficit

Table 2. Characterization of the sample of students with outcome below 58 points and odds ratio values $(n=687)$. Show children`s outcomes. Age: average in years $\pm \mathrm{SD}=10.99 \pm 0.91$

\begin{tabular}{lcc}
\multicolumn{1}{c}{ Variables } & $\%$ & OR \\
\hline Sex & & \\
Female & $42.4(n=291)$ & 0.6892 \\
Male & $57.6(n=397)$ & 1.45 \\
Fathers' education level & & \\
Illiterate & $0.2(n=2)$ & 2.227 \\
Elementary education & $45.4(n=312)$ & 1.569 \\
Secondary education & $15.9(n=110)$ & 0.6152 \\
Higher education & $3.34(n=240)$ & 0.5107 \\
N/A & $35.16(n=240)$ & - \\
Mothers' education level & & \\
Illiterate & $0.4(n=3)$ & 2.413 \\
\hline Elementary education & $50.07(n=345)$ & 2.267 \\
Secondary education & $17.6(n=121)$ & 0.5174 \\
Higher education & $4.2(n=29)$ & 0.4109 \\
N/A & $27.73(n=189)$ & \\
Social level of the schools & & \\
A & 0 & - \\
B & $4.4(n=30)$ & 0.4709 \\
C & $29.5(n=203)$ & 0.9507 \\
D & $66.1(n=454)$ & 2.227 \\
E & 0 & - \\
\hline SD: standard deviation; OR: odds ratio; Cl: confidence interval; $95 \%$ Cl for OD. \\
\hline
\end{tabular}

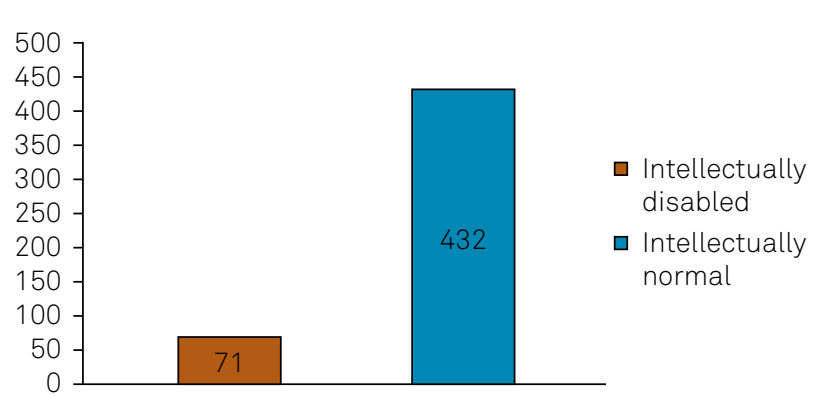

Figure 2. Results of the WISC-R for the sample of students below 60 ( $n=503$ ), shows that 184 students were excluded due to change of address, or because their parents had not signed the informed consent form. The WISC-R showed that 71 children were considered intellectually disabled. 
hyperactivity disorder (ADHD). However, the author points out the fact that the study had been conducted with children who attended the public educational system. Another factor is related to diagnostic criteria for DD, which should be better defined, distinguishing children who have mathematics difficulty by means of other factors.

O'Hare et al. ${ }^{2}$ concluded that the DD was infrequent. However, Kosc ${ }^{9}$ estimated $6.4 \%$ in Slovakia, Von Aster $^{10}$ found $4.4 \%$ in Germany, Lewis et al. ${ }^{11}$ found $3.6 \%$ in

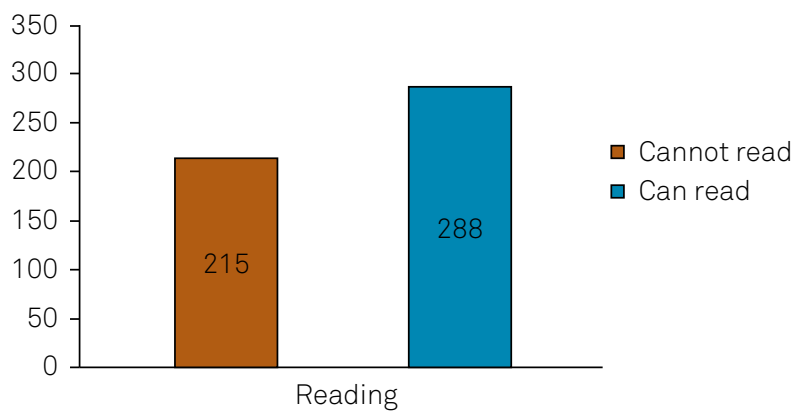

Figure 3. Outcomes of reading skill assessed concurrently with the application of the WISC-R $(n=503)$, shows that, of 503 children, 215 had reading difficulty considered serious.

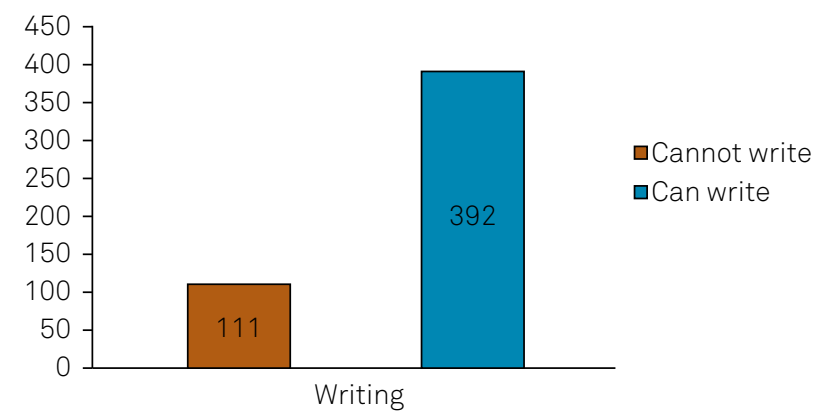

Figure 4. Outcomes of writing skill assessed concurrently with the application of the mathematics protocol (Bastos, 2003; modified from Grafman and Boller's $\left.{ }^{(8)}\right)(n=503)$, shows that, of 503 children, 111 children had writing difficulty.
England, Badian et al. ${ }^{12}$ found $6.4 \%$ in the United States, and Reigosa-Crespo et al. ${ }^{13}$ found $3.4 \%$ in Cuba. These studies draw attention to the fact that mathematics difficulty and the DD should be distinguished.

Hein, Bzufka, and Neumärker ${ }^{14}$ assessed children of urban and rural areas in Germany and found a prevalence of 6.6 and $6.59 \%$, respectively. Koumoula et al. $^{15}$ assessed the urban and rural population in Greece and found a much greater prevalence in rural areas. This finding is compatible with the sample of the present study. Even though the rural area has not been assessed, it was demonstrated that the social level of the neighborhood in which a school is located is relevant for the prevalence of DD.

The present study also showed that there was greater prevalence of DD in male individuals. Studies conducted by Benbow and Stanley ${ }^{16,17}$ showed a better performance in male

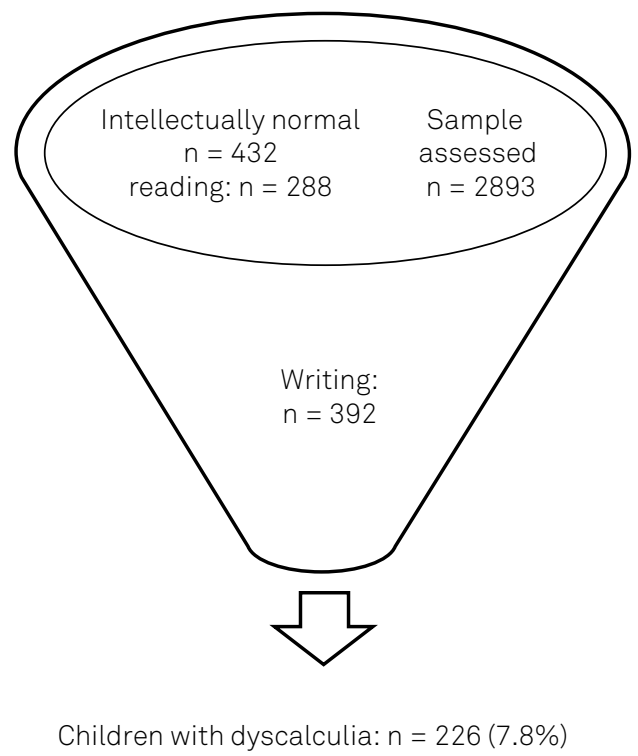

Figure 5. Final results for prevalence of dyscalculia, show that, of the 2,893 children included in the study, 226 could read and write, were intellectually normal, and were suffering from dyscalculia (7.8\%).

Table 3. Data correlation. When children's performance was compared with the vulnerability of the neighborhoods in which the schools were located, it was found that the performance was lower between the extremes. The result of the comparison between very low vulnerability and medium vulnerability was significant ( $p$-value $=0.0453$ ). When sex was compared, there were a greater number of boys with dyscalculia than girls, with a significant $p$-value ( $p$-value $=0.048$ ).

\begin{tabular}{|c|c|c|c|}
\hline A & B & C & $\mathrm{D}$ \\
\hline Parent's education level & Social level of school & $\begin{array}{l}\text { Individual social level of neighborhood's } \\
\text { schools }\end{array}$ & $\begin{array}{l}\text { Prevalence of dyscalculia } \\
\text { according to sex (\%) }\end{array}$ \\
\hline Mother's education level & $X^{2}=6.048$ & Very low vulnerability vs. Low vulnerability & Male \\
\hline$X^{2}=2.2240$ & p value = 0.0486 (significant) & $X^{2}=5.432$ & $56.6(n=128)$ \\
\hline$p$ value $=0.0002$ (significant) & & $p$ value $=0.1380$ (non-significant) & \\
\hline Father's education level & & $\begin{array}{l}\text { Very low vulnerability vs. Medium } \\
\text { vulnerability }\end{array}$ & Female \\
\hline$X^{2}=1.8094$ & & $X^{2}=4.007$ & $43.4(n=98)$ \\
\hline \multirow[t]{4}{*}{$p$ value $=0.0029$ (significant) } & & $p$-value $=0.0453($ significant $)$ & \\
\hline & & Low vulnerability vs. Medium vulnerability & Total \\
\hline & & $X^{2}=0.7312$ & $100(n=226)$ \\
\hline & & $p$-value $=0.3925$ & $p$-value $=0,048$ \\
\hline
\end{tabular}


individuals, but their studies were conducted with intellectually competent adolescents attending high school and the authors attributed these results to environmental factors.

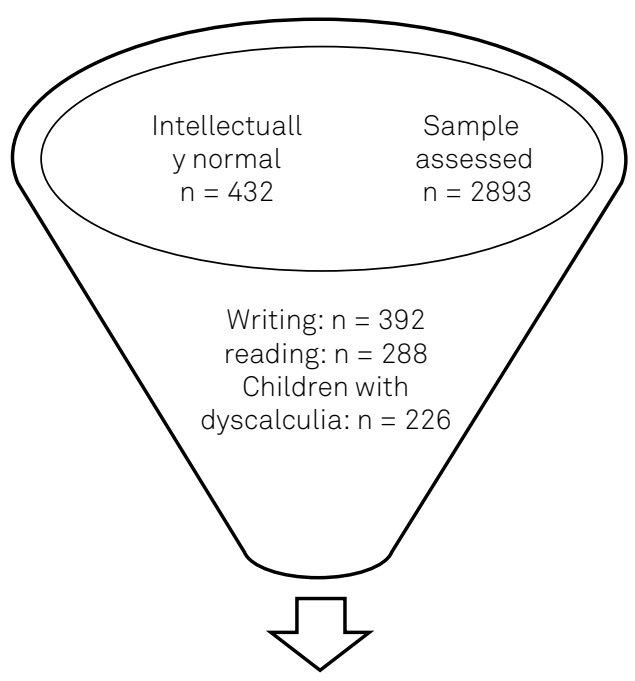

Children with dyscalculia associated with reading/writing disorders: $n=431$ (14.9\%)

Figure 6. Final results for prevalence of dyscalculia associated with reading and writing disorders, shows that, when children with reading and writing disorders were added, mathematics impairment was greater, with a total of 432 children corresponding to $14.9 \%$.

Table 4. Relationship between performing calculations and mathematical reasoning $x$ calculation. Shows that, excluding the tests of mathematical problems there was no change in the prevalence of dyscalculia. $X 2=0.7312 ; p$-value $=0.3925$ value (non-significant)

\begin{tabular}{lcc}
\hline Performance & Below 60 & $\begin{array}{c}\text { Children with } \\
\text { dyscalculia }\end{array}$ \\
\hline $\begin{array}{l}\text { Calculation and mathematical } \\
\text { reasoning }\end{array}$ & 687 & 226 \\
$\begin{array}{l}\text { Calculation (Excluding the } \\
\text { questions of mathematical } \\
\text { reasoning from the protocol) }\end{array}$ & 1,006 & 226 \\
\hline
\end{tabular}

Wei et al. ${ }^{18}$ assessed children in rural and urban areas of Great Beijing and found better performance of girls in the tasks of subtraction, complex multiplication, numeric comparison, and completing numerical series. The authors attributed these results to better language processing. Recently a study in Serbia, supported by the Ministry of Education, showed a prevalence of $9.9 \%$, number greater than the world average (3-6\%), being attributed to socioeconomic factors ${ }^{19}$. Limitations of this study was to have been used a non-validated test because in our country there is no gold standard test, also the children evaluated were the public schools, for lack of accession of private schools.

Because of the catastrophic consequences for the individual and for the country, and there is a clear relationship between educational level, employment and gross domestic

Product of a Nation (OECD), more investments should be made in research and educational policies.

In conclusion, studies in other Brazilian regions with different socioeconomic characteristics are needed in order to find the real prevalence of developmental dyscalculia. Mathematics difficulty as a result of other causes is numerically higher, disorder such as attention deficit and anxiety to mathematics, which read as mathematics in difficulty. A clinical situation commonly associated is attention deficit disorder with or without hyperactivity, which implies drug treatment with good results ${ }^{20}$. Therefore, careful assessments must be performed to diagnose a medical situation that requires interdisciplinary teams, with consequent rehabilitation strategies, as well as other centers using computer resources such as Rescue Calcularis ${ }^{21}$, and Race Number ${ }^{22,23}$. It is essential to raise teachers' awareness emphasizing that this group of children should be identified and referred for assessment, thus avoiding inappropriate "labels" and certainly compromising their future, closing the doors of colleges, technical courses, and decent jobs, not allowing them to enter into the labor market, which has become increasingly competitive.

\section{References}

1. Associação Americana de Psiquiatria. Manual diagnóstico e estatístico de transtornos mentais (DSM-IV). Porto Alegre: Artes Médicas; 1995.

2. O'Hare AE, Brown JK, Aitken K. Dyscalculia in children. Dev Med Child Neurol. 1991;33(4):356-61. doi:10.1111/j.1469-8749.1991.tb14888.x

3. Gross-Tsur V, Manor O, Shalev RS. Developmental dyscalculia: prevalence and demographic features. Dev Med Child Neurol. 1996,38(1):25-33. doi:10.1111/j.1469-8749.1996.tb15029.x

4. Shalev RS. Developmental dyscalculia.J Child Neurol. 2004;19(10):765-71. doi:10.1177/08830738040190100601

5. Boller F, Grafman J. Acalculia. In: Frederiks JAM. Clinical neuropsychology. Handb Clin Neurol. 1986;45:473-81.
6. Oishi J, Martins RA, Manzato AJ, Ferrari F, Leme EMMT, Mantovani LR et al. Social diagnostic project of São José do Rio Preto city, SP. In: Book of abstracts of the RSAI World Congress 2008; 2008; São Paulo, SP. São Paulo, SP: Faculdade de Economia e Administração da USP; 2008.

7. Wechsler, D. Wechsler Intelligence Scale for Children; WISC-R. Revised edition (1974).

8. Powell, A. How Sputnik changed U.S. education. Harvard Gazette, 11 Oct 2007. Available from: http://news.harvard.edu/gazette/story/2007/10/ how-sputnik-changed-u-s-education/ acessed 15.10.2012

9. Kosc L. Developmental dyscalculia. J Learn Disabil. 1974;7(3):46-59. doi:10.1177/002221947400700309 
10. Aster M. Developmental dyscalculia in children: Review of the literature and clinical validation. Acta Paedopsychiatr. 1994;56(3):169-78.

11. Lewis $C$, Hitch GJ, Walker P. The prevalence of specific arithmetic difficulties and specific reading difficulties in 9- to 10-year old boys and girls. J Child Psychology and Psychiatric. 1994;35(2):283-92. doi:10.1111/j.1469-7610.1994.tb01162.x

12. Badian NA. Arithmetic and nonverbal learning. In: Myklebust HR (Ed.). Progress in learning disabilities. New York: Grune and Stratton; 1983. Vol 5, p. 235-64.

13. Reigosa-Crespo V, Valdés-Sosa M, Butterworth B, Estévez N, Rodríguez M, Santos E et al. Basic numerical capacities and prevalence of developmental dyscalculia: the Havana Survey. Dev Psychol. 2012;48(1):123-35. doi:10.1037/a0025356

14. Hein J, Bzufka MW, Neumärker KJ. The specific disorder of arithmetic skills. Prevalence studies in a rural and an urban population sample and their clinico-neuropsychological validation. Eur Child Adolesc Psychiatry. 2000;9(2),S87-101. doi:10.1007/s007870070012

15. Koumoula A, Tsironi V, Stamouli V, Bardani I, Siapati S, Annika $G$ et al. An epidemiological study of number processing and mental calculation in Greek schoolchildren. J Learn Disabil. 2004;37(5):377-88. doi:10.1177/00222194040370050201

16. Benbow CP, Stanley JC. Sex differences in mathematical ability: fact or artifact? Science. 1980;210(4475):1262-4. doi:10.1126/science.7434028
17. Benbow CP, Stanley JC. Sex differences in mathematical reasoning ability: more facts. Science. 1983;222(4627):1029-31. doi:10.1126/science.6648516

18. Wei W, Lu H, Zhao H, Chen C, Dong Q, Zhou X. Gender differences in children's arithmetic performance are accounted for by gender differences in language abilities. Psychol Sci. 2012;23(3):320-30. doi:10.1177/0956797611427168

19. Jovanović G, Jovanović Z, Banković-Gajić JB, Nikolić A, Svetozarević $\mathrm{S}$, Ristic D. The frequency of dyscalculia among primary school children. Psychiatr Danub. 2013;25(2):170-4.

20. Lindsay RL, Tomazic T, Levine MD, Accardo PJ. Impact of attentional dysfunction in dyscalculia. Dev Med Child Neurol. 1999;41(9):639-42. doi:10.1017/S0012162299001309

21. Kucian K, Grond U, Rotzer S, Henzi B, Schönmann C, Plangger $\mathrm{F}$ et al. Mental number line training in children with dećvelopmental dyscalculia. Neuroimage. 2011;57(3):782-95. doi:10.1016/j.neuroimage.2011.01.070

22. Wilson AJ, Revkin SK, Cohen D, Cohen L, Dehaene S. An open trial assessment of "The Number Race", an adaptive computer game for remediation of dyscalculia. Behav. Brain Funct. 2006,2(1):20. doi:10.1186/1744-9081-2-20

23. Number Race 27/11/2012 - Software designed for remediation of dyscalculia (or mathematical learning disabilities) in children aged 4-8 and for teaching number sense. 